\title{
КРИТИЧЕСКИЙ АНАЛИЗ НОРМАТИВНОЙ БАЗЫ ПО УЧЕТУ ДЕЛОВОЙ РЕПУТАЦИИ КОМПАНИИ И ОСНОВНЫЕ НАПРАВЛЕНИЯ ДАЛЬНЕЙШЕГО РАЗВИТИЯ
}

\section{A CRITICAL ANALYSIS OF THE NORMATIVE BASE FOR THE GOODWILL OF THE COMPANY AND MAIN DIRECTIONS OF FURTHER DEVELOPMENT}

Yu. Klimashina

Summary. The business reputation of the organization is undoubtedly a very complex economic and accounting category, and like any accounting category it should be determined, reflected in the accounts of the company and in the statements of the company. Based on the analysis of Russian and international accounting standards, the article reveals the inconsistency of the category "business reputation of the organization" with the economic sense. Due to the revealed contradictions, it is proposed to revise the traditional ideas about the essence of the business reputation of the organization as an accounting category and an object of accounting. So, it is proposed to critically evaluate the conformity of the concept of "business reputation of an organization" in the form in which domestic and foreign regulatory regulations offer us the requirements and criteria imposed not only on intangible assets, but also on non-current assets in general. Based on an analysis of the actual practical experience of the sale and purchase transactions of a ready-made business, it is proposed to replace the ownership of the property complex as an object of the transaction that determines the emergence of business reputation, ownership of a legal entity acquired through financial investments. Based on the author's reasoning given in this article, it is proposed to consider the possibility of amending regulatory documents on accounting the prerequisites for recognition and the order of reflection of the business reputation life cycle in the accounting system, as well as in the company's statements. This will increase the reliability of financial statements, reduce the risk of user decisions made on the basis of such reports, and increase the openness and transparency of such transactions.

Keywords: goodwill, grounds for identification, valuation, accounting, impairment, economic benefits, depreciation, reporting.

\section{Ввецение}

B условиях неопределенности и риска, присущих современному развитию экономики страны, особое внимание уделяется достоверности бухгалтерской отчетности компании, на основе которой субъекты экономических отношений принимают множество
Климашина Юлия Сергеевна

К.э.н., дочент, Сибирский государственный индустриальный университет, Новокузнецк positivism@rambler.ru

Аннотация. Деловая репутация организации, несомненно, является весьма сложной экономической и бухгалтерской категорией, и, как любая бухгалтерская категория, она должна быть определена, отражена на счетах учета и в отчетности компании. В статье на основе анализа российских и международных стандартов учета раскрывается несоответствие категории «деловая репутация организации» экономическому смыслу. Вследствие выявленных противоречий предлагается пересмотреть традиционное представление о сущности деловой репутации организации как бухгалтерской категории и объекта учета. Так, предлагается критически осмыслить соответствие понятия «деловая репутация организации» в том виде, в котором сегодня предлагают нам отечественные и зарубежные нормативные регулятивы, требованиям и критериям, предъявляемым не только к нематериальным активам, но и к внеоборотным активам в целом. На основе анализа реального практического опыта сделок купли-продажи готового бизнеса предлагается произвести замену права собственности на имущественный комплекс как объект сделки, определяющей возникновение деловой репутации, правом собственности на юридическое лицо, приобретаемым посредством финансовых вложений. На основе авторской аргументации, приведенной в данной статье, предлагается рассмотреть возможность внесения изменений в нормативные документы по бухгалтерскому учету предпосылок признания и порядка отражения жизненного цикла деловой репутации в системе бухгалтерских счетов, а также в отчетности компании. Это позволит повысить достоверность бухгалтерской финансовой отчетности, снизить степень риска принимаемых на основе такой отчетности решений пользователей, повысить открытость и прозрачность подобных сделок.

Ключевые слова: деловая репутация, основания идентификации, оценка, порядок учета, обесценение, экономические выгоды, амортизация, отчетность.

разнообразных решений в зависимости от своих целей. Бухгалтерская отчетность полностью формируется на основе точного и полного отражения на счетах учета всех происходящих в компании хозяйственных операций и процессов. Каждому факту хозяйственной жизни, связанному с изменением структуры актива и (или) пассива компании, в нормативной базе уделено отдельное 
положение по ведению бухгалтерского учета, в котором прописаны особенности учета, оценки и отражения в отчетности различных элементов имущества и обязательств компании.

Особое внимание уделяется тем объектам, которые отражаются в учете и учитываются в отчетности в большей мере лишь на основе профессионального суждения, так как, являясь весьма дискуссионными, в нормативной базе не нашли полного освещения. Одним из таких объектов в теории бухгалтерского учета и в практике счетоведения принято считать деловую репутацию организации.

Рост публикационной активности ученых, занимающихся вопросами учета и оценки деловой репутации, подчеркивает актуальность данной темы. Следует обратить особое внимания на тот факт, что подавляющее большинство исследований ведется в контексте действующих отечественных и международных стандартов учета и отчетности, принимаемых за истину в последней инстанции и практически не подвергаемых критическому осмыслению [1-7].

\section{Метомы и материалы}

Эмпирической базой исследования послужили изучение и анализ российского и международного опыта учета и отражения в отчетности результатов сделок купли-продажи готового бизнеса в условиях, когда рыночная стоимость компании отличается от балансовой. Методологической базой исследования послужили работы отечественных и зарубежных авторов, занимавшихся в разные периоды времени вопросами идентификации и оценки деловой репутации. [8-13]

В ходе написания статьи применялись эвристические и логические методы исследования, позволяющие критически оценить действующий порядок учета деловой репутации и предложить дальнейшие направления развития и совершенствования нормативной базы для повышения не только качества учетных данных, но и достоверности финансовой отчетности в целом.

\section{Результаты}

Оценка стоимости компании всегда представляла собой сложный процесс, еще более сложной является денежная оценка такого нематериального актива, как деловая репутация организации. Согласно и российскому, и международному законодательству, возможность интерпретировать деловую репутацию как объект бухгалтерского учета (то есть отражать на счетах учета и в отчетности компании) возникает только в момент совершения факта купли-продажи предприятия [1, 2].
В случае, если рыночная стоимость компании выше ее балансовой, возникает положительная деловая репутация организации, которая рассматривается компанией-покупателем как будущие экономические выгоды и подлежит отражению в бухгалтерском финансовом учете как отдельный инвентарный объект. Отрицательная деловая репутация рассматривается как скидка и отражается на финансовом результате компании в качестве расходов. [1]

Российская и международная практика отражения деловой репутации в бухгалтерском учете представляется достаточно противоречивой. Конечно, наравне с правами собственности на приобретаемое предприятие (в рамках налогового законодательства и согласно действующему порядку отражения на счетах бухгалтерского учета приобретаемого имущественного комплекса) покупатель приобретает и ее деловую репутацию. Однако данный факт противоречит главному и единственному нормативному документу по учету деловой репутации ПБУ 14/2007, в котором данной категории посвящен целый раздел, трактующий приобретенную деловую репутацию как особый вид нематериального актива, не обладающий признаком идентифицируемости, а значит и неспособный быть отчужденным от своего носителя.

Согласно нормативным актам по бухгалтерскому учету, приобретенная деловая репутация в виде надбавки к балансовой стоимости компании должна учитываться в составе нематериальных активов [1]. Однако, несомненно, есть ряд несоответствий деловой репутации классическим признакам идентификации как первого, так и второго вида активов.

Рассматривая природу деловой репутации и оценивая ее с точки зрения признания в качестве нематериальных активов, обращает на себя внимание тот факт, что деловую репутацию компании невозможно отделить от других активов компании, а также отсутствие документов, подтверждающих существование деловой репутации и прав на нее. То есть налицо явное нарушение двух из семи признаков, перечисленных в главном нормативном документе по учету НМА, которые должны выполняться еще и единовременно [1]. Уже на этом этапе возможность отнесения деловой репутации к составу нематериальных активов, согласно действующему законодательству, представляется сомнительной.

Изучая природу деловой репутации в качестве отнесения ее к внеоборотным активам в цзелом, мы наблюдаем еще больше противоречий с нормативной базой. Принципиальная невозможность отчуждения деловой репутации и, следовательно, ее автономной продажи ставит под сомнение тот факт, что предприятие, прода- 
ваемое как имущественный комплекс, выше балансовой стоимости ее активов, способно сгенерировать нематериальные активы. Наряду с множеством других проблем, в качестве основной представляется также невозможность установления конкретного способа участия деловой репутации в производстве продукции, выполнении работ, оказании услуг и управлении организацией (как следствие - ставится под большой вопрос целесообразность амортизации как таковой).

Интересен тот факт, что и в российском, и в международном законодательстве рассмотрены лишь случаи покупки компаний друг другом. Но ведь это далеко не единственный случай, когда возникают все основания для признания деловой репутации в бухгалтерской практике. При приобретении компании по стоимости выше балансовой, например, индивидуальный предприниматель, находящийся на упрощенной системе налогообложения, не осуществляет ведения бухгалтерского учета и формирования финансовой отчетности в полном объеме, таким образом, не отразит данный факт в своем учете, хотя все требования к ее признанию и соблюдены.

В части налогового законодательства нет никакой мотивации отражения в учете и отчетности деловой репутации субъектами малого бизнеса. Если организация платит единый налог с доходов, нет никакого интереса пытаться отразить в отчетности деловую репутацию, так как это никак не повлияет на уплачиваемые налоги; если же налог уплачивается с разницы между доходами и расходами, положительную деловую репутацию в составе расходов учитывать нельзя, основанием является тот факт, что данный вид расходов не поименован [4, статья 346.16].

Законодательно закрепленный действующий алгоритм расчета стоимости деловой репутации, признанный на сегодняшний день научным и профессиональным сообществом, является причиной искажения рыночной стоимости бизнеса, а иногда и срыва коммерческих сделок. Ведь единственной «зацепкой» для расчета стоимости ее в российской практике является разница между продажной стоимостью компании и стоимостью по балансу всех ее активов и обязательств.

Согласно нормативным документам по бухгалтерскому учету [1] и гражданскому законодательству [3], расчет деловой репутации (а как следствие - последующее отражение в отчетности) сводится к чисто арифметическим действиям. На сегодняшний день в различных учебниках по бухгалтерскому учету приводится корреспонденция счетов, связанная не с непосредственным учетом этого феномена, а с учетом тех активов и обязательств, права собственности по которым перешли покупателю.
Недооценивая значимость данного показателя и его роль для компании в будущие периоды (в частности изза отсутствия гармонизации в нормативных документах), покупатель заинтересован, скорее, в приобретении отрицательной деловой репутации, то есть скидки с цены, нежели гудвилла (надбавки за балансовую стоимость компании), что само по себе, в терминах общепринятой бухгалтерской интерпретации деловой репутации, является крайне нелогичным.

Согласно действующему законодательству, по сути, чисто арифметическую разницу сегодня относят в состав нематериальных активов и обязывают отражать в отчетности компаний. Этим и объясняется тот факт, что на практике найти отчетность, составленную по российским требованиям, в составе которой была бы отдельной строкой выделена деловая репутация, практически невозможно.

В условиях агрегированности баланса при отнесении вышеописанной разницы в состав нематериальных активов это, скорее, приведет к дезинформации пользователей, нежели к достоверности такой отчетности.

Рост доли внеоборотных активов в рамках экспресс-анализа бухгалтерской финансовой отчетности достаточно часто трактуется как свидетельство повышения надежности предприятия и усиления гарантий интересов инвесторов и кредиторов, однако в рассматриваемой ситуации вывод подобного рода оказывается весьма сомнительным.

Замена права собственности на имущественный комплекс как объект сделки, определяющей возникновение деловой репутации в российских и международных стандартах, правом собственности на юридическое лицо, приобретаемым посредством финансовых вложений, по мнению автора, позволит учитывать возникающую разницу в качестве деловой репутации экономически обоснованно [14].

В данном случае необходимы некоторые уточнения. В частности, если у покупателя нет намерений ликвидировать или перепродавать данное предприятие, он приобретает акции компании или доли, входя в состав учредителей / собственников, обеспечивая «целостность» всех элементов приобретаемой организации (наработанные деловые связи, клиентскую базу, выгодное месторасположение, опыт управления и уровень квалификации персонала и т.д.), эффект от взаимодействия которых и создает деловую репутацию; достоверность информации, отражаемой в учете и отчетности, несомненно, возрастет.

Дальнейшая оценка приобретенной деловой репутации организации в российской и международной 
практике разнятся. Так, в ПБУ 14/2007 единственно возможный вариант заключается в ее амортизации, то есть постепенном переносе стоимости будущих экономических выгод на финансовые результаты компании в течение 20 лет, но с некой оговоркой: не более срока деятельности организации. Амортизационные отчисления по положительной деловой репутации организации отражаются в бухгалтерском учете путем равномерного уменьшения ее первоначальной стоимости (линейным способом) [1].

Согласно международным требованиям, деловая репутация, приобретенная в результате бизнес-комбинации (при объединении бизнеса), амортизации не подвергается, а подлежит обязательному ежегодному тестированию на предмет обесценения [7].

По существу, тестирование предполагает необходимость ежегодной справедливой оценки деловой репутации и выявления величины ее возможного обесценения, относимого на финансовый результат (убыток).

Главной сложностью, непосредственно связанной с профессиональным суждением бухгалтера, является определение так называемой «ценности от использования». Ценность от использования представляет собой дисконтированную стоимость ожидаемых денежных потоков. При этом очевидно, что деловая репутация сама по себе, автономно от других активов или их групп неспособна обеспечивать приток денежных средств, однако во многих случаях она участвует в создании денежных потоков опосредованно, через так называемые «генерирующие единицы», которые представляют собой наименьшие определяемые группы активов, обеспечивающие приток денежных средств, независимый от притоков денежных средств, генерируемых другими активами или группами активов.

Высокая степень субъективности оценок при проведении тестирования деловой репутации на обесценение, согласно международным требованиям, является наиболее веским аргументом против применения данного метода и определения главного вектора развития этого направления. Кроме того, не стоит упускать из внимания момент оценки того, что оказывает влияние на прогнозируемые денежные потоки: приобретенная деловая репутация или внутрисозданная, которая в неявном виде запрещена к отражению в учете современными бухгалтерскими (российскими и международными) стандартами.

Одной из альтернатив подходу периодического тестирования на обесценение является систематическая амортизация деловой репутации в течение определенного срока полезного использования. Невозможность прове- дения амортизации подчеркивает не только сомнительный факт отнесения деловой репутации в состав нематериальных активов, описанный выше, но и возможность продолжения признания актива финансовой отчетности в случае, если он будет продолжать приносить сверхприбыли по окончании определенного срока [14].

Интересным представляется тот факт, что, несмотря на периодически вносимые поправки и рассмотрение проекта документа ФСБУ «Нематериальные активы», разработчики и многие ученые не рассматривают тот факт, что приобретенная деловая репутация может не только обесцениваться, амортизироваться или оставаться на том же уровне, но и расти.

Для дальнейшего развития нормативной базы с целью повышения достоверности и прозрачности бухгалтерской финансовой отчетности целесообразно рассмотреть возможность перехода от амортизации и теста на обесценение к ежегодному проведению теста на изменение стоимости деловой репутации с отражением суммы возможного роста и снижения ее величины.

Действующая корреспонденция счетов по учету возникновения и дальнейшей оценки деловой репутации не позволит провести ежегодное тестирование на изменение стоимости приобретенной деловой репутации.

Сам факт того, что приобретенная деловая репутация отражается бухгалтерской проводкой Д 04 «Нематериальные активы» К 76 «Расчеты с прочими дебиторами и кредиторами», по сути, нарушает принцип имущественной обособленности, так как источником возникновения деловой репутации служит не само предприятие в результате слаженности работы, а его собственник, кредиторская задолженность перед которым у нас и возникает.

По поводу амортизации и проведения теста на обесценение в статье приведено множество доводов о том, что необходимы существенные изменения в этом направлении.

Для повышения аналогичности и прозрачности учета и отчетности к счету 04 «Нематериальный актив» можно открыть субсчет, например, «Приобретенная деловая репутация». В качестве корреспондирующего счета целесообразно рассмотреть использование счета 83 «Добавочный капитал», к которому также можно открыть субсчет 83, например, «Приобретенная деловая репутация». Причем данная корреспонденция счетов не нарушает и, более того, согласована с действующим планом счетов [15].

Д 04 «субсчет Приобретенная деловая репутация» К 83 «субсчет Приобретенная деловая репутация»- 
Таблица 1. Фрагмент бухгалтерского баланса организации-покупателя согласно действующим нормативным актам

\begin{tabular}{|c|c|c|c|}
\hline Показатель & Сумма & Показатель & Сумма \\
\hline \multicolumn{2}{|l|}{ АКТИВ } & \multicolumn{2}{|l|}{ ПАССИВ } \\
\hline \multicolumn{2}{|l|}{ I Внеоборотные активы } & \multicolumn{2}{|l|}{ V Краткосрочные обязательства } \\
\hline Нематериальные активы & + & Заемные средства & $\ldots$ \\
\hline $\begin{array}{l}\text { Результаты } \\
\text { исследований и разработок }\end{array}$ & $\ldots$ & Кредиторская задолженность & + \\
\hline Основные средства & $\ldots$ & Доходы будущих периодов & $\ldots$ \\
\hline Финансовые вложения & $\ldots$ & Оценочные обязательства & $\ldots$ \\
\hline Прочие внеоборотные активы & $\ldots$ & Прочие обязательства & $\ldots$ \\
\hline Итого по разделу I & $\ldots$ & Итого по разделу V & r \\
\hline
\end{tabular}

Таблица 2. Фрагмент бухгалтерского баланса организации-покупателя согласно описанным предложениям

\begin{tabular}{|c|c|c|c|}
\hline Показатель & Сумма & Показатель & Сумма \\
\hline \multicolumn{2}{|l|}{ АКТИВ } & \multicolumn{2}{|l|}{ ПАССИВ } \\
\hline \multicolumn{2}{|l|}{ I Внеоборотные активы } & \multicolumn{2}{|l|}{ III Капитал и резервы } \\
\hline Нематериальные активы & + & Уставный капитал & $\ldots$ \\
\hline $\begin{array}{l}\text { Результаты } \\
\text { исследований и разработок }\end{array}$ & $\cdots$ & Переоценка внеоборотных активов & $\ldots$ \\
\hline Основные средства & $\cdots$ & $\begin{array}{l}\text { Добавочный капитал } \\
\text { Приобретенная деловая репутация }\end{array}$ & + \\
\hline Финансовые вложения & $\ldots$ & Резервный капитал & $\ldots$ \\
\hline Прочие внеоборотные активы & $\ldots$ & Нераспределенная прибыль & $\ldots$ \\
\hline Итого по разделу I & $\ldots$ & Итого по разделу III & $\ldots$ \\
\hline
\end{tabular}

признание деловой репутации в результате выгодного приобретения контрольного пакета акций

Дальнейшее проведение теста на изменение стоимости приобретенной репутации возможно привязать (в случае если акции предприятия котируются на фондовой бирже) к росту стоимости этих акций, так как на это напрямую оказывает влияние формируемая деловая репутация. В случае, если акции компании не котируются на рынке, дальнейшую оценку можно привязать именно к чистой прибыли компании, рост которой вызывается в том числе за счет синергии всех факторов деловой репутации.

Если в результате проведенного теста произошел рост величины деловой репутации, предлагается на эту сумму делать проводку: Д 04 «субсчет Приобретенная деловая репутация» К 83 «субсчет Приобретенная деловая репутация».

Если же наблюдается снижение, то отображать его следует обратной корреспонденцией счетов: Д 83 «суб- счет Приобретенная деловая репутация» К 04 «субсчет Приобретенная деловая репутация»

Сегодня при формировании бухгалтерской финансовой отчетности приобретенную деловую репутацию показывают в I и V разделах баланса по статьям «Нематериальные активы» и «Кредиторская задолженность». В таблице 1 наглядно представлено, какое отражение, согласно нормативным документам по бухгалтерскому учету, найдет данный факт в отчетности.

Анализируя данную отчетность, становится невозможным оценить, как в последующие периоды будет меняться величина приобретенной деловой репутации. По сути, оценка выгодности приобретения бизнеса становится в ряд текущих задач.

В случае если стоимостный эквивалент приобретенной деловой репутации будет учитываться на счетах 04 и 83 и отражаться в I и III разделах баланса», это позволит в течение всего срока существования деловой репута- 
ции компании отслеживать ее динамику, как представлено в таблице 2.

\section{ВывО $\triangle \mathrm{b}$}

Следует отметить, что в бухгалтерском балансе уже отдельной строкой выделили статью «Переоценка внеоборотных активов»; если добавятся строки «Приобретенная деловая репутация» в I и V разделах, то прозрачность отчетности и возможность на ее основе принимать экономические решения будут более обоснованными.
В настоящее время Министерством финансов ведется глобальная разработка федеральных стандартов бухгалтерского учета и внесение поправок в уже изданные положения. В случае если предлагаемые автором данной статьи направления дальнейшего развития совершенствования учета и отражения в отчетности показателя деловой репутации будут включены в качестве поправок в ПБУ 14/2008 с описанием причин возникновения, корреспонденцией счетов, а также отражением в балансе компании, достоверность данных финансовой отчетности вырастет в разы.

\section{ЛИТЕРАТУРА}

1. Об утверждении Положения по бухгалтерскому учету «Учет нематериальных активов» (ПБу 14/2007): Приказ Минфина России от 27.12 .2007 № 153 н (ред. от 16.05.2016) // СПС КонсультантПлюс.

2. Международный стандарт финансовой отчетности (IAS) 38 «Нематериальные активы»: [введен в действие на территории Российской Федерации Приказом Минфина России от 25.11.2011 № 160 н] (ред. от 30.10.2018) (с изм. и доп., вступ. в силу с 01.01.2019).

3. Гражданский кодекс Российской Федерации. Часть первая: Федеральный закон от 30.11.1994 № 51-Ф3 (ред. от 03.08.2018) // СПС КонсультантПлюс.

4. Налоговый кодекс Российской Федерации. Часть вторая: Федеральный закон № 117-Ф3 (статья 25) (ред. 21.05.2019). // СПС КонсультантПлюс.

5. Международный стандарт финансовой отчетности (IFRS) 3 «Объединения бизнеса» (ред. от 26.08.2015) // СПС КонсультантПлюс

6. Международный стандарт финансовой отчетности (IFRS) 13 «0ценка справедливой стоимости» (ред. от 11.07.2016) // СПС КонсультантПлюс.

7. Международный стандарт финансовой отчетности (IAS) 36 «0бесценение активов» (ред. от 27.06.2016) // СПС КонсультантПлюс.

8. Кузубов, С. А. Развитие концептуальных подходов к измерению гудвилл с исторической перспективы. Ч. 2 / С. А. Кузубов // Корпоративные финансы.2014.— № 4 (32). — С. 128-148.

9. Соколов, Я. В. Гудвилл: новая категория бухгалтерского учета / Я. В. Соколов, М. Л. Пятов // Бухгалтерский учет.— 1997.— № 2.— С. 46-50.

10. Гудвил: синергетическая сущность, оценка, учет, анализ: монография / А. Е. Иванов, Н. А. Соколова, Н. В. Генералова, Е. Ю. Саломатина; под науч. ред. А. Е. Иванова.— Москва: РИОР: ИНФРА-М, 2019. 227 с.

11. Генералова, Н. В. Учет обесценения активов на примере обесценения гудвилла как область применения профессионального суждения / Н. В. Генералова, Н. А. Соколова // Международный бухгалтерский учет. — 2014. — № 26- С. 2-14.

12. Brown J. December 1998 — the season of goodwill. Accountancy Publ. 1998. № 121. P. 61.

13. Bryer R.A. A political economy of SSAP 22: Accounting for goodwill. British Accounting Review, 1995, no. 27, pp. 283-310.

14. Климашина, Ю. С. Альтернативный подход к учету деловой репутации организаций / Ю. С. Климашина // Журнал Аудитор.— 2015.— № 10.—C. 42-49.

15. План счетов бухгалтерского учета финансово-хозяйственной деятельности организации и Инструкция по его применению:Приказ Минфина от 31.10 .2000 г. № 94 н // СПС КонсультантПлюс 